\title{
Isolation and identification of Haemophilus ducreyi in a clinical laboratory
}

\author{
S. W. LUBWAMA*, F. A. PLUMMER, J. NDINYA-ACHOLA, H. NSANZE, W. NAMAARA, L. J. \\ Department of Medical Microbiology, University of Nairobi, College of Health Sciences, P.O. Box 30588 , \\ Nairobi, Kenya
}

Summary. Routine procedures used to isolate Haemophilus ducreyi in a busy
laboratory are reported. Identification was based on colony morphology and
nutritional and biochemical properties of 120 fresh isolates of $H$. ducreyi. These
isolates grew very well on Gonococcal Agar and Mueller-Hinton Agar incubated at
$34^{\circ} \mathrm{C}$ in candle extinction jars containing moistened filter paper. Colonies varied in
size, giving a polymorphic appearance. They were smooth, dome-shaped, and buff-
yellow to grey in colour, and measured $2 \mathrm{~mm}$ in diameter. They could be pushed intact
across the agar surface. By microscopic examination of gram-stained smears the
isolates were gram-negative coccobacilli arranged in short chains, clumps or whorls
and occasionally in typical "rail track" arrangements. Individual bacteria showed
bipolar staining. Colonies autoagglutinated in saline. All strains were catalase-
negative and did not produce indole or $\mathrm{H}_{2} \mathrm{~S}$. They were oxidase- and $\beta$-lactamase
positive and required $\mathrm{X}$ but not $\mathrm{V}$ factor for growth. Now that reliable techniques have
been developed and characteristics established it is possible for most clinical
laboratories to isolate and identify this organism from most patients with chancroid.

\section{Introduction}

Chancroid is a common sexually-transmitted disease (STD) in many parts of the tropics (Kibukamusoke 1965; Nsanze et al., 1981). Evidence of sporadic outbreaks in various temperate countries over the past few years also exists. The causative organism, Haemophilus ducreyi, was recognised in stained smears of ulcer exudates by Auguste Ducrey in 1889 , but his attempts to culture it were unsuccessful. The first isolation has been variously credited to Lenglet in 1898, Bezancom, Griffin and LeSourd in 1900, Petesen in 1895 or Istoamanov and Akopiantz in 1897 (Ronald and Albritton, 1984); these early workers used media and techniques of unknown sensitivity and specificity. Until recently, examination of gram-stained exudate was relied upon for the laboratory diagnosis of the soft chancre, despite its dubious reliability (Chapel et al., 1977; Nsanze et al., 1981; Choudhary et al., 1982). Because of difficulties encountered in isolating the organism by culture and the gradual disappearance of endemic chancroid in industrialised nations, interest in the bacterium waned.

Received 20 Aug. 1985; accepted 12 Dec. 1985.

*Present address, to which requests for offprints should be sent; Department of Clinical Microbiology, King Fahd Central Hospital, P.O. Box 204, Gizan, Saudi Arabia.
A resurgence of interest occurred when Hammond et al. (1978a) developed a selective agar for the isolation of $H$. ducrey $i$ during an urban epidemic of chancroid in Canada. Their medium consisted of Gonococcal Agar with bovine haemoglobin 1\%, Isovitalex $1 \%$ and vancomycin $3 \mathrm{mg} / \mathrm{L}$. Nsanze et al. (1981) reported the isolation of $H$. ducreyi from $70 \%$ of patients with clinical chancroid in Nairobi using Hammond's medium modified by the addition of $5 \%$ fetal calf serum. Similar isolation rates of $H$. ducreyi were obtained in Johannesburg by Bilgeri et al. (1982); they used Mueller-Hinton Agar with chocolated horse blood $5 \%$, Isovitalex $1 \%$ and vancomycin $3 \mathrm{mg} / \mathrm{L}$. Nsanze et al. (1984) compared Gonococcal Agar medium with Mueller-Hinton Agar medium for the primary isolation of $H$. ducreyi from genital ulcers in Kenya and found that the use of the two media together increased the yield of positive cultures; they recommended the use of both in STD laboratories.

$H$. ducreyi has few demonstrable biochemical characteristics (Ronald and Albritton 1984) because of its fastidious growth requirements. Reports on the key identification tests of this organism grown on different media are conflicting (Sottnek et al., 1980; Sturm and Zanen, 1984; Taylor et al., 1984). Furthermore, there is speculation that different biotypes of this organism may 
exist in different parts of the world (Sturm and Zanen, 1984). This situation may be due to lack of well-defined techniques for growing the organism on proven media leading to specific identification. We now report the development of routine isolation and identification procedures and observations on the morphological, nutritional and biochemical characteristics of $H$. ducreyi strain isolated on the two media in Nairobi during the period Jun.-Sep. 1984.

\section{Materials and methods}

\section{Patients and specimens}

Male patients with genital ulcers were examined on presentation at the Nairobi City Special Treatment Clinic (STC). If any ulcer had a dry scab this was elevated and removed with the broken end of a swab stick. Dry cotton swabs were used to collect exudates from the bases of the lesions. In the clinic, specimens were inoculated directly (but not spread) on two media: GC Agar base (Gibco Diagnostic, Madison, WI) containing bovine haemoglobin $2 \%$, Isovitalex $1 \%$ and vancomycin $3 \mathrm{mg} / \mathrm{L}$ (GC-Hgs) Mueller-Hinton Agar base (Baltimore Biological Laboratories, Becton-Dickinson Company, Cockeysville, MD) containing chocolated horse blood $5 \%$, Isovitalex $1 \%$ and vancomycin $3 \mathrm{mg} / \mathrm{L}$ (MH-HB).

\section{Isolation and identification of strains}

On return to the laboratory 2-3 h later, the GC-Hgs and $\mathrm{MH}-\mathrm{HB}$ plates were streaked with wire loops to give single colony isolations. The plates were then incubated at $34 \mathrm{C}$ in a candle extinction jar with a moistened filter paper to provide a $\mathrm{CO}_{2}$-enriched, water-vapour saturated atmosphere. Plates were examined after incubation for 48 $\mathrm{h}$ and those which showed poor growth or none were reincubated and re-examined daily for up to 5 days. $H$. ducreyi isolates were identified by typical colony morphology and colour, and appearance in gram-stained smears.

\section{Biochemical tests}

Catalase activity was measured by dropping $\mathrm{H}_{2} \mathrm{O}_{2} 5 \%$ $\mathrm{v} / \mathrm{v}$ on the colonies on clean glass slides. Staphylococcus aureus and Streptococcus pyogenes were used as control organisms.

Oxidase production was detected by the method of Kovacs (1956) with tetramethyl-p-phenylenediamine; Escherichia coli and Neisseria gonorrhoeae were control organisms.

$\beta$-Lactamase activity was detected with chromogenic cephalosporin (Nitrocefin, Glaxo) in a cup of a microtitration plate, with $S$. aureus and Str. pyogenes as control organisms.

$\mathrm{H}_{2} \mathrm{~S}$ production on Isovitalex-enriched chocolated agar medium was sought with lead-acetate paper (Cowan 1974). Proteus vulgaris and E. coli were used as control organisms.
Indole production was detected by the method of Clarke and Cowan (1952) with E. coli and Klebsiella pneumoniae as controls. Furthermore X-and V-factor tests were performed with impregnated paper strips (Taxo Haemophilus Differentiation strips; BBL). Strips containing (i) haemin $4000 \mu \mathrm{g}$, (ii) NAD $100 \mu \mathrm{g}$, and (iii) haemin $2000 \mu \mathrm{g}$ plus NAD $100 \mu \mathrm{g}$, were placed on plates of Mueller-Hinton Agar base inoculated with the organisms; $\boldsymbol{H}$. influenzae was the control organism. Freshly isolated strains were always subcultured into chocolatedagar stabs or skimmed milk; these were kept at $-70^{\circ} \mathrm{C}$ before shipment to Professor A.R. Ronald, University of Manitoba, Winnipeg, Canada, for further structural analysis.

\section{Results}

A total of 120 isolates of $H$. ducreyi was obtained. Very good growth of all the strains was observed on both media. They grew well at $34^{\circ} \mathrm{C}$ after incubation for $48 \mathrm{~h}$. Growth was enhanced by $\mathrm{CO}_{2}$ and a proportion of isolates, particularly on primary isolation, appeared to be $\mathrm{CO}_{2}$ dependent. Increased humidity facilitated the growth of most strains. On most occasions a candle extinction jar containing a moistened filter paper incubated at $34^{\circ} \mathrm{C}$ provided an excellent environment for the culture of the organism. Growth was scanty after $24 \mathrm{~h}$ and the typical colonies were usually apparent only after 48-72 h. Colonies varied in size so that the variation in size and opacity often gave the impression of a mixed culture. Most colonies measured $2 \mathrm{~mm}$ in diameter. They were pinpoint, smooth, domeshaped and buff-yellow to grey. The most remarkable feature was the extreme cohesiveness of the colony, allowing it to be nudged intact across the agar surface. It was not always easy to make a uniform suspension of the colonies in saline because the organisms stuck together in clumps. Microscopic examination of gram-stained films of colonies from solid media showed gram-negative coccobacilli in short chains, clumps or whorls, and at times in the typical rail-track arrangement. Bipolar staining could be observed in some.

All isolates were catalase-negative, and $\beta$-lactamase- and oxidase-positive. They produced neither indole nor $\mathrm{H}_{2} \mathrm{~S}$. They required haemin (factor $\mathrm{X}$ ) for growth but not NAD (factor V).

\section{Discussion}

In most North American and European STD clinics chancroid occurs too infrequently to warrant routine culture of genital ulcers for $H$. ducreyi. In epidemic settings such as the recent outbreak in California (Centers for Disease Control, 1982), culture for $H$. ducrey $i$ has been performed on all patients with genital ulcers. In most tropical ende- 
mic areas such as Kenya (Nzanze et al., 1981; Piot et al., 1983; Plummer et al., 1983) improved techniques allow reliable isolation. Unfortunately, in developing countries laboratory resources cannot be made available to permit routine culture, but central laboratories should be able to undertake periodic surveys of genital ulcers to confirm the proportion due to $H$. ducreyi and to collect strains for determination of antimicrobial susceptibility patterns. Culture may also be required to establish a diagnosis in unusual or complicated patients.

Five thousand patients with probable chancroid are seen at the Nairobi City STC each year but only selected males with chancroid were included in the present study. Whilst use of heat-inactivated serum or clotted blood is no longer necessary because several agar media have been developed (Sottnek et al., 1980; Bilgeri et al., 1982; Nsanze et al., 1984), it is possible that strain-specific variations of nutritional requirements occur. It is evident however, that all strains require a source of haemin and serum for optimal isolation. The addition of vancomycin makes media selective for $H$. ducreyi. An additional inhibitor such as polymyxin may be added (Plummer et al., 1984). Penicillin or ampicillin would also be possible selective agents where, as in Nairobi, $H$. ducreyi produces $\beta$-lactamase (Fast et al., 1982).

We recommend direct inoculation of media for luxuriant growth. No transport systems have been evaluated for maintaining $H$. ducreyi before primary isolation, but Amies' transport medium has been used with considerable success (Choudhary $e t$ al., 1982).

The role of Gram's stain in the diagnosis of $H$. ducreyi infection in patients with genital ulcers remains controversial. Direct microscopic examination of smears from genital ulcers is not routine practice in this laboratory as, although few gramnegative organisms share the classical spatial distribution of $H$. ducreyi, in practice this characteristic appearance is rarely demonstrated in ulcer exudate (Nzanze et al., 1981). Some authorities have found the evidence of gram-stained smears to be specific and sensitive (Taylor et al., 1984), but others have

\section{REFERENCES}

Bilgeri Y R, Ballard R C, Duncan M O, Mauff A C, Koornhoff H J U 1982 Antimicrobial susceptibility of 103 strains of Haemophilus ducreyi isolated in Johannesburg. Antimicrobial Agents and Chemotherapy 22:686-688.

Center for Disease Control 1982 Chancroid-California. Morbidity and Mortality Weekly Report 31:173-175. not (Chapel et al., 1977; Nsanze et al., 1981; Choudhary et al., 1982).

The features of $H$. ducreyi on the media we describe are usually adequate for presumptive diagnosis in experienced hands. Additionally the typical rail track alignment of gram-stained organisms from culture plates can be helpful. The oxidase reaction depends upon the method used (Nobre 1982). It is uniformly positive if NNNN-tetramethyl-p-phenylenediamine is used as substrate but can be variable or negative when $\mathrm{NN}$-dimethyl- $p$ phenylenediamine is used (Sottnek et al., 1980). The catalase test has consistently been reported to be negative. However, Sturm and Zanen (1984) reported the tube test to be positive for all of their 29 isolates.

The porphyrin test is the preferred method for demonstrating the dependence of $H$. ducreyi strains on exogenous haemin (Hammond et al., 1978b), but this requires special equipment and is not yet a routine procedure. This is also the case with the nitrate reductase and alkaline phosphatase tests (Sturm and Zanen, 1984). Moreover, tests for carbohydrate utilisation have been previously demonstrated to be negative (Kilian, 1976) and thus are not applicable in a busy laboratory. A comprehensive scheme for systematic identification of $H$. ducreyi has just been produced by Plummer et al. (1984). Such an algorithm will be very useful in larger regional STD reference laboratories which are well equipped and well stocked with reagents.

After primary isolation, most strains of $\mathrm{H}$. ducreyi rapidly adapted to chocolated-agar media containing serum but without antibiotic. When subcultured in enriched chocolated agar stabs, organisms survived for up to 4 weeks. Strains could also be stored in serum or skimmed milk at $-40^{\circ} \mathrm{C}$ to $-70^{\circ} \mathrm{C}$ for longer periods. This survival enabled the transportation of $H$. ducreyi isolates from Nairobi to Winnipeg for further characterisation (McNicol and Ronald, 1984). These co-ordinated studies will determine whether different biotypes of $H$. ducreyi postulated by Sturm and Zanen (1984) do occur.
Chapel T A, Brown W J, Jeffriec C, Stewart J A 1977. How reliable is the morphological diagnosis of penile ulcerations? Sexually Transmitted Diseases 4:150-152.

Choudhary B P, Kumari S, Bhatia R, Agarwal D S 1982 Bacteriologic study of chancroid. Indian Journal of Medical Research 76:379-385.

Clarke P H, Cowan S T 1952 Biochemical methods for bacteriology. Journal of General Microbiology 6:187-197. 
Cowan ST 1974 Cowan and Steel's manual for the identification of medical bacteria, 2nd edn. Cambridge University Press, Cambridge.

Fast M V et al. 1982 Treatment of chancroid by clavulanic acid with amoxycillin in patients with $\beta$-lactamase-positive Haemophilus ducrevi infection. Lancet 2:509-511.

Hammond G W, Lian C J, Wilt J C. Ronald A R 1978a Comparison of the specimen collection and laboratory techniques for isolation of Haemophilus ducreyi. Journal of Clinical Microbiology 7:39-43.

Hammond G W, Lian C J, Wilt J C, Albritton W L, Ronald A R $1978 \mathrm{~b}$ Determination of the haemin requirement of Haemophilus ducreyi: evaluation of the porphyrin test and media used in the satellite growth test. Journal of Clinical Microbiology 7:243-246.

Kibukamusoke J W 1965 Venereal disease in East Africa. Transactions of the Royal Society of Tropical Medicine and Hyiene 59:642 648.

Kilian M 1976 A taxonomic study of the genus Haemophilus, with the proposal of a new species. Journal of General Microbiology 93:9-62.

Kovacs N 1956 Identification of Pseudomonas pyocyanea by the oxidase reaction. Nature 178: 703 .

McNicol P J, Ronald A R 1984 The plasmids of Haemophilus ducreyi. Journal of Antimicrobial Chemetherapy 14:561-564.

Nobre G N 1982 Identification of Haemophilus ducreyi in the clinical laboratory. Journal of Medical Microbiolog. 15:243 245.

Nsanze H, Fast M V. D'Costa L J, Tukei P, Curran J, Ronald A
R 1981 Genital ulcers in Kenya; a clinical and laboratory study. British Journal of Venereal Diseases 57:378-381.

Nsanze $\mathrm{H}$ et al. 1984 Comparison of media for the primary isolation of Haemophilus ducreyi. Sexually Transmitted Diseases 11:6-9.

Piot P, Slottmans L, Nsanze H, Ronald A R 1983 Isolating Haemophilus ducreyi. Lancet 2:909-910.

Plummer F A, D'Costa L J, Nsanze H, Dylewski J, Karasira P, Ronald A R 1983 Epidemiology of chancroid and Haemophilus ducreyi in Nairobi, Kenya. Lancet 2:1293-1295.

Plummer F A, Kraus S J, Sottnek F O, Albritton W L 1984 Chancroid and granuloma inguinale. In: Wentworth B B, Judson $F \mathbf{N}$ (eds) Laboratory methods for the diagnosis of sexually transmitted diseases. American Public Health Association, Washington DC, pp 193-211.

Ronald A R, Albritton W L 1984 Chancroid and Haemophilus ducreyi. In: Holmes K K et al. (eds) Sexually transmitted diseases. McGraw-Hill Book Company, New York pp 385393.

Sottnek F O, Biddle J W, Krams S J, Weaver R E, Stewart J A 1980 Isolation and identification of Haemophilus ducreyi in a clinical study. Journal of Clinical Microbiology 12:170 174.

Sturm A W, Zanen H C 1984 Enzymic activity of Haemophilus ducreyi. Journal of Clinical Microbiology 18:181-187.

Taylor D N et al. 1984 The role of Haemophilus ducreyi in penile ulcers in Bangkok, Thailand. Sexually Transmitted Diseases 11:148-151. 